\title{
Basic research in otolaryngology
}

This issue of The Journal of Laryngology \& Otology features two review articles that focus on areas of basic research in our specialty. Wormald and colleagues review the topic of regenerative medicine. ${ }^{1}$ Tissue engineering holds great potential to restore structure and function following resection for disease or congenital abnormality, with tracheal regeneration being at the forefront. This type of fundamental research in which human tissue is used for therapeutic and diagnostic purposes is key to many future advances. ${ }^{2}$ Another review article, by Ramakrishnan and colleagues, discusses the importance of biofilms in the pathogenesis of rhinosinusitis. ${ }^{3}$ Evidence suggests that biofilms, particularly Staphylococcus aureus, are important in the more severe cases of rhinosinusitis, and that successful therapy will need to include anti-biofilm strategies. ${ }^{4}$

Two additional articles cover perhaps more mundane, everyday areas of otolaryngology. Over the past years, with the advent of more minimally invasive nasal surgery, there has been a move away from routine nasal packing following nose and sinus surgery. Sahin and Aras investigate the discomfort of nasal packing and whether infiltration of local anaesthetic solution (lidocaine) into the nasal pack reduces discomfort. ${ }^{5}$ Although local anaesthetic in nasal packs reduced pain, the use of nasal packing was still associated with considerable patient anxiety. The authors recommend avoiding using packing whenever possible. Finally, an article by Khan and colleagues investigates the evidence for the use of head bandages following middle-ear surgery, and finds that their use has very little evidence base. ${ }^{6}$ The authors suggest that head bandages may not be required after routine middle-ear surgery. The need to critically evaluate new as well as established practices has fortunately attracted much more attention of late. ${ }^{7}$

ROBIN YOUNGS EDWARD FISHER Senior Editors

\section{References}

1 Wormald JC, Fishman JM, Juniat S, Tolley N, Birchall MA. Regenerative medicine in otorhinolaryngology. J Laryngol Otol 2015;129:732-9

2 Warner E, Birchall M, Lowdell MW. Tissue banking in ENT: challenges and methods. J Laryngol Otol 2013;127:630-7

3 Ramakrishnan Y, Shields RC, Elbadawey MR, Wilson JA. Biofilms in chronic rhinosinusitis: what is new and where next? $J$ Laryngol Otol 2015;129:744-51

4 Tan NC, Drilling AJ, Jardeleza C, Wormald PJ. Is nasal steroid spray bottle contamination a potential issue in chronic rhinosinusitis? J Laryngol Otol 2014;128(suppl 1):S28-33

5 Sahin C, Aras HI. Effect on patient anxiety of lidocaine infiltration into nasal packing after septoplasty: prospective, controlled study. J Laryngol Otol 2015;129:784-7

6 Khan I, Mohamad S, Ansari S, Iyer A. Are head bandages really required after middle-ear surgery? A systematic review. $J$ Laryngol Otol 2015;129:740-3

7 Aval S, Pabla L, Flood LM. The National Institute for Health and Clinical Excellence, and otolaryngology: review of the evidence. J Laryngol Otol 2014;128:2-12 